\title{
THE NEUROPSYCHIATRY OF INBORN ERRORS OF METABOLISM
}

Mark Walterfang ${ }^{1,2}$, Olivier Bonnot ${ }^{3,}$, Ramon Mocellin $^{1,2}$, Dennis Velakoulis ${ }^{1,2}$

Correspondence: Mark Walterfang

Level 2, John Cade Building

ROYAL MELBOURNE HOSPITAL 3050 AUSTRALIA

T: +61393428750 F: +61393428483

Search Terms: inborn errors of metabolism, lipidoses, myelin, neurodevelopment, psychiatric illness

Running Head: Neuropsychiatry of IEM

Word Count: 7191 words

Abstract: 205 words

Title: 50 characters

Tables: $0 \quad$ Figures: 0

${ }^{1}$ Melbourne Neuropsychiatry Centre, University of Melbourne and Melbourne Health, Parkville, Australia

${ }^{2}$ Neuropsychiatry Unit, Royal Melbourne Hospital, Parkville, Australia

${ }^{3}$ Department of Child and Adolescent Psychiatry CHU, University of Nantes, Nantes, France 


\section{CONFLICT OF INTEREST STATEMENT}

Dr Walterfang has served on a scientific advisory board and as a consultant for and received funding for travel from Actelion Pharmaceuticals Ltd; and received royalties from the publication of Kaplan and Sadock's Comprehensive Textbook of Psychiatry (Lippincott Williams \& Wilkins, 2009).

Dr Bonnot has served on a scientific advisory board and as a consultant for and received funding for travel from Actelion Pharmaceuticals Ltd and receives research support from the Ministry of Health, France.

Dr Mocellin reports no relevant disclosures.

Dr Velakoulis has received royalties from the publication of Kaplan and Sadock's Comprehensive Textbook of Psychiatry (Lippincott Williams \& Wilkins, 2009) and receives research support from NHMRC. 


\begin{abstract}
A number of metabolic disorders that affect the central nervous system can present in childhood, adolescence or adulthood as a phenocopy of a major psychiatric syndrome such as psychosis, depression, anxiety or mania. An understanding and awareness of secondary syndromes in metabolic disorders is of great importance as it can lead to the early diagnosis of such disorders. Many of these metabolic disorders are progressive and may have illness-modifying treatments available. Earlier diagnosis may prevent or delay damage to the central nervous system and allow for the institution of appropriate treatment and appropriate family and genetic counselling.
\end{abstract}

Metabolic disorders appear to result in neuropsychiatric illness either through disruption of late neurodevelopmental processes (metachromatic leukodystrophy, adrenoleukodystrophy, GM2 gangliosidosis, Niemann-Pick type C, cerebrotendinous xanthomatosis, neuronal ceroid lipofuscinosis, and alpha mannosidosis) or via chronic or acute disruption of excitatory/inhibitory or monoaminergic neurotransmitter systems (acute intermittent porphyria, maple syrup urine disease, urea cycle disorders, phenylketonuria and disorders of homocysteine metabolism).

In this manuscript we review the evidence for neuropsychiatric illness in major metabolic disorders and discuss the possible models for how these disorders result in psychiatric symptoms. Treatment considerations are discussed, including treatment resistance, the increased propensity for side-effects and the possibility of some treatments worsening the underlying disorder. 


\section{INTRODUCTION}

Metabolic disturbance can have wide-ranging effects on the central nervous system (CNS), as highly metabolically active neurons are variably sensitive to derangements in metabolic processes (Schreiber and Baudry, 1995). Disruption to metabolic processes results in marked disruption to normal CNS function and development, with presentations ranging from gross neurodevelopmental disruption, seizures and coma when disruption is severe, to intermittent and/or subtle cognitive and behavioural disturbance when disruption is mild. Inborn errors of metabolism (IEM) result from the absence or deficiency of an intrinsic component of a metabolic pathway, often an enzyme, which disrupts cellular function due to impairment in synthesis of cellular components essential to neuronal function, or the accumulation of neurotoxic substances (Saudubray, 2009). Many IEMs have attenuated forms that present for the first time in adulthood (Sedel et al., 2007) without preceding overt clinical symptoms in childhood. Three quarters of all psychiatric illness presents prior to the age of 24 (Kessler et al., 2005) and the majority of these disorders have strong genetic and biological underpinnings (Inoue and Lupski, 2003). It could be therefore expected that IEMs that present in adolescence or early adulthood will have a greater likelihood of presenting with psychiatric illness (Walterfang et al., 2009b).

It has long been recognised that mental illness can result directly from organic brain disease and that psychiatric disorder may be the first presentation of a more systemic illness (Lipowski, 1984). A number of brain disorders can produce an accurate phenocopy of psychiatric illness, where the presentation is indistinguishable from a primary psychiatric disorder. As many disorders that cause organic psychiatric syndromes have their own definitive non-psychiatric treatment, many of the secondary psychiatric syndromes may be partially or totally reversible. This is particularly true in metabolic disorders, many of which are treatable with dietary modification, enzyme replacement, or other specific biochemical therapy. Awareness of the types of disorders that may present as psychiatric illness phenocopies and their associated physical, cognitive or neurological concomitants allow clinicians to recognise an underlying systemic or metabolic illness. Conversely, failure to recognise the underlying illness whilst focussing on treatment for the secondary 
psychiatric syndrome alone can delay the institution of appropriate treatment and result in potentially irreversible CNS change.

The purpose of this review is to describe the major metabolic disorders that are associated with secondary psychiatric illness. Given that most psychiatric illness has its onset in adolescence or early adulthood, our focus is on disorders that present in or persist into adulthood. We will then propose a number of neurobiological models that allow an understanding of how metabolic disorders can result in secondary psychiatric syndromes and describe general principles of management of these syndromes. 


\section{METACHROMATIC LEUKODYSTROPHY}

In younger patients with metachromatic leukodystrophy (MLD, OMIM: 250100), seizures, mental retardation and motor symptoms predominate while psychiatric manifestations and dementia frequently present prior to motor or cognitive symptoms in adult-onset patients. The adult form presents as one of two distinct phenotypes, one with a predominantly motor (cerebello-pyramidal) presentation and the other with a predominantly psychiatric presentation. The latter appears to be strongly associated with the I179S mutation (Rauschka et al., 2006). Up to half of patients with onset between 10 and 30 years of age present with psychotic symptoms, including auditory hallucinations, delusions, formal thought disorder, and catatonia (Rosebush et al., 2010). As the illness progresses, other neurological symptoms supervene, including seizures, chorea or dystonia. Neurological symptoms commonly present after the development of psychiatric symptoms (Black et al., 2003; Hyde et al., 1992; Rosebush et al., 2010). Patients often present with attentional disturbance, reduced speed of processing and executive impairment, typical of reduced frontal-subcortical connectivity (Shapiro et al., 1994). Some adult-onset patients may initially be diagnosed as frontotemporal dementia (Kozian et al., 2007). MRI generally demonstrates typical confluent periventricular white matter changes sparing subcortical U-fibres, with leukodystrophy frequently showing a frontotemporal preponderance with only minimal involvement of grey matter (Reider-Grosswasser and Bornstein, 1987).

Adolescent/adult MLD provides an intriguing model for the understanding of the neurobiology of psychosis, as it interrupts myelinative processes that occur during this critical period of neurodevelopment, in particular frontotemporal myelination (Hyde et al., 1992; Walterfang et al., 2005). As frontotemporal connectivity is known to be impaired at both structural and functional levels in schizophrenia (Friston and Frith, 1995; Pettersson-Yeo et al., 2011), the unique predilection of MLD for frontotemporal anatomical connections appears to confer its psychotogenic propensity. This suggests that any CNS process that interrupts the normal development of connectivity between these cortical regions in this crucial "psychotogenic window" can produce psychosis (Black et al., 2003; Walterfang et al., 
2005). It is notable that some treatment-refractory patients with schizophrenia have been shown to have ASA pseudo-deficiency or intermediate ASA levels (Fluharty, 1990), suggesting that this may be an independent risk factor in the population for psychotic illness. 


\section{GM2 GANGLIOSIDOSIS: TAY-SACHS DISEASE}

In Tay-Sachs disease (TSD, OMIM: 272800) ,HEX-A deficiency in lysosomes impairs the catabolism of gangliosides from the neuronal cell membrane, resulting in accumulation of lysosomal gangliosides. This results in neuronal ultrastructural change, particularly axon hillock outgrowth to form meganeurites with ectopic dendritogenesis (Purpura and Suzuki, 1976) and axonal spheroids (Walkley, 1988), which may alter neuron-to-neuron microconnectivity initially before neuronal death occurs. Neurons in the thalamus, substantia nigra, cerebellum and brainstem are particularly affected (Suzuki, 1991). Unlike early-onset cases, late-onset patients' cortical neurons show little to no excess ganglioside storage (Kornfeld, 2008).

The neurological presentation of late-onset TSD is quite variable and no distinct phenotype-genotype correlations exist (Federico et al., 1991a). Patients will frequently present with gait disturbance, dysarthria and tremor (MacQueen et al., 1998). Many patients have normal or near-normal cognitive function (MacQueen et al., 1998), although subtle deficits in executive function, processing speed and verbal memory may be present in up to half of patients (Elstein et al., 2008; Frey et al., 2005; Zaroff et al., 2004). Neuroimaging findings in TSD describe cerebellar atrophy in most patients (Frey et al., 2005; Neudorfer et al., 2005; Streifler et al., 1989), although cerebral atrophy may be present in up to a quarter of patients (Frey et al., 2005). Diagnosis generally rests on demonstration of deficient hexosaminidase activity.

Neuropsychiatric presentations occur in up to half of late onset TSD patients described in unselected series (Gravel et al., 2001) and the most common neuropsychiatric presentation is psychosis (Frey et al., 2005; Navon et al., 1986; Neudorfer et al., 2005; Oates et al., 1986; Streifler et al., 1993). The rate of schizophrenia-like psychosis in late-onset TSD patients ranges from 30\% (Oates et al., 1986) to $50 \%$ (Navon et al., 1986). In a review of all published cases prior to 1998, a conservative estimate of prevalence of psychosis in late-onset patients was one third (MacQueen et al., 1998). Catatonia may be the initial presenting feature (Renshaw et al., 1992; Rosebush et al., 1995; Streifler et al., 1989). Mania or depression has also been described (Argov and Navon, 1984; Federico et al., 1991b; Hamner, 1998). 
The treatment of psychosis in TSD can be problematic, with often only partial response to neuroleptics and mood stabilisers such as lithium (Hurowitz et al., 1993; MacQueen et al., 1998; Rosebush et al., 1995; Streifler et al., 1989). Importantly, patients with late-onset TSD are exquisitely sensitive to the motor side-effects of typical neuroleptic medications (Manor et al., 1997; Rosebush et al., 1995; Streifler et al., 1989). For severe psychotic or affective illness, electroconvulsive therapy (ECT) appears to be a safe and effective treatment (Hurowitz et al., 1993; Renshaw et al., 1992). 


\section{ADRENOLEUKODYSTROPHY}

In X-linked adrenoleukodystrophy (ALD, OMIM: 300100), the adult cerebral form shows a predilection for neuropsychiatric presentations. Demyelinative changes are most prominent in parietal and occipital cortex as well as the thalamus, callosum and brainstem (Patel et al., 1995), although more anterior cortical regions can be involved in a minority of patients (Castellote et al., 1995; MacDonald et al., 1984). MRI generally shows symmetrical hyperintensity beginning in the posterior callosum and spreading into parieto-occipital regions on T2-weighted imaging (Poll-The and Gartner, 2012).

At presentation, the majority of adult-onset cerebral ALD patients present with psychiatric disturbance, most commonly behavioural changes (Rosebush et al., 2010). Mania and affective psychosis appear to be the most common neuropsychiatric presentations, more so than schizophreniform illnesses, although the latter do occur (Rosebush et al., 2010; Walterfang et al., 2005). Patients are not infrequently treatment-resistant (Rosebush et al., 2010). As in MLD, psychiatric presentations in ALD may precede frank motor or cognitive changes by some years (Rosebush et al., 1999).

The andrenomyeloneuropathy (AMN) form of ALD, the most common form of ALD amongst adults and long thought to affect only the peripheral nervous system, subtle cerebral manifestations of the disorder are often present, and the rate of depressive illness appears to be elevated at least two-fold (Walterfang et al., 2007). Some patients may present with mood changes subsequent to adrenal insufficiency, which reverse with appropriate corticosteroid replacement therapy. As patients progress, most will develop significant neuropsychological disturbance, characterised by a frontal-subcortical pattern of impairment (Luda and Barisone, 2001), a pattern which may also appear in an attenuated form in many AMN patients (Edwin et al., 1990). As in MLD, when white matter changes occur in anterior cortical regions, patients may present with a clinical presentation that initially may be indistinguishable from frontotemporal dementia (Inoue et al., 2012). 


\section{NIEMANN-PICK TYPE C DISEASE}

Niemann-Pick Type C disease (NPC, OMIM: 607625) is characterised neuropathologically by in axonal spheroid formation, hypomyelination and eventual demyelination (Karten et al., 2003) and impaired synaptic function (Byun et al., 2011; Pressey et al., 2012). White matter tracts are severely affected (Ong et al., 2001; Palmeri et al., 1994; Zervas et al., 2001) with the corpus callosum showing the most striking axonal loss (German et al., 2002). The neuronal cells most vulnerable to these pathological processes are the Purkinje cells of the cerebellum, striatum, and thalamus followed by neurons in hippocampal and other cortical regions (Elleder et al., 1985; Harzer et al., 1978; March et al., 1997; Ong et al., 2001).

Structural imaging in NPC commonly shows diffuse cerebral and/or cerebellar atrophy (Fink et al., 1989; Lossos et al., 1997; Schiffman, 1996; Shulman et al., 1995b; Tedeschi et al., 1998), atrophy of striatum, thalamus and hippocampi (Walterfang et al., 2010; Walterfang et al., 2012b), midbrain atrophy (Walterfang et al., 2012a) and pathology in major white matter tracts including the corpus callosum (Grau et al., 1997; Palmeri et al., 1994; Walterfang et al., 2011; Walterfang et al., 2010). Neuropsychological testing in adolescent/adult-onset cases often reveals a steady decline in function throughout adulthood with significant deficits in executive function and memory (Campo et al., 1998; Schiffman, 1996; Shulman et al., 1995a; Shulman et al., 1995b).

Psychosis is a common initial presentation of adolescent or adult-onset NPC and may present alongside motor symptoms and cognitive impairment as an initial manifestation in 25-40\% of adult-onset cases (Josephs et al., 2003; Walterfang et al., 2006a). When psychosis has been reported, features have included persecutory delusions, auditory hallucinations and ideas of reference (Breen et al., 1981; Campo et al., 1998; Josephs et al., 2003; Shulman et al., 1995a; Shulman et al., 1995b; Walterfang et al., 2009a; Walterfang et al., 2006b). A small number of cases have been reported where psychosis was the sole initial manifestation (Shulman et al., 1995a; Shulman et al., 1995b; Turpin et al., 1991; Vanier, 1999; Walterfang et al., 2006a), and these patients may be treated with neuroleptics alone for a number of years before gait impairment and cognitive decline result in a diagnostic revision 
(Josephs et al., 2003; Shulman et al., 1995b; Walterfang et al., 2006a; Walterfang et al., 2009a). We have also described a presentation in adulthood with rapid-cycling bipolar disorder that responded to anticonvulsant medication (Sullivan et al., 2005). 


\section{CEREBROTENDINOUS XANTHOMATOSIS}

Cerebrotendinous xanthomatosisis (CTX, OMIM: 213700) results in cholestanol accumulation in white and grey matter, leading to neuroaxonal dystrophy and axonal dropout, severe white matter pathology (Soffer et al., 1995) and accelerated apoptosis (Moghadasian et al., 2002). Global reduction in grey and white matter volume, reduced white matter integrity and callosal atrophy are noted on structural imaging (Berginer et al., 1994; Chang et al., 2010; Dotti et al., 1994; Guerrera et al., 2010; Su et al., 2010; Wallon et al., 2010). MRS findings suggest that axonal metabolic dysfunction rather than demyelination are responsible for the diffuse white matter findings (De Stefano et al., 2001).

Two case series of CTX patients with psychiatric disturbance have been reported. In the first, 4 of 35 cases suffered psychiatric disturbance, three of these being neuroleptic-responsive psychotic illness (Berginer et al., 1988). A further series found psychiatric disturbance in 7 of 10 CTX patients, predominantly agitation and psychosis (Dotti et al., 1991). Other authors have reported depression in CTX sufferers (Chen et al., 2012b; Lee et al., 2002; Shapiro, 1983) and more recently a fronto-temporal dementia picture in a compound heterozygote has been described (Guyant-Marechal et al., 2005). 


\section{NEURONAL CEROID LIPOFUSCINOSIS}

The characteristic neuropathology of adult neuronal ceroid lipofuscinosis (ANCL) is accumulation of lipofuscin-like material in lysosomes in neuronal and extraneuronal tissue (Wisniewski et al., 2001). The distribution of abnormal lysosomal inclusions in neurons is commonly diffuse through cortical and subcortical neurons, but may be localised to the cerebral cortex in a quarter of cases (Constantinidis et al., 1992). Hippocampal/enterorhinal cortex may be particularly susceptible (Braak and Braak, 1993). MRI often shows cerebral and cerebellar atrophy, callosal thinning, and may show other features such as altered signal in subcortical nuclei, whilst SPECT commonly shows regional cortical hypoperfusion (D'Incerti, 2000; Sayit et al., 2002; Schreiner et al., 2000).

Neuropsychiatric disturbance in adolescent or adult-onset cases is very common (Berkovic et al., 1988; Goebel and Braak, 1989). ANCL presents with psychosis in up to $20 \%$ of patients, with ages of onset between 13 and 41 (Augustine et al., 1993; Callagy et al., 2000; Charles et al., 1990; Gospe and Jankovic, 1986; Hinkebein and Callahan, 1997; Lewandowska et al., 2009; Reif et al., 2003; Tobo et al., 1984; Waldman, 1992), with psychotic symptoms also described in juvenile patients (Vercammen et al., 2003). Backman et al, in a series of juvenile NCL patients (mean age 15 years), described five adolescent patients with psychotic symptoms warranting psychotropic medication, although affective symptoms (predominantly depression) were more common (Backman et al., 2005). Nijssen et al described a pedigree with an autosomal dominant inheritance where three of six affected family members presented with psychosis (Nijssen et al., 2009). Characteristic psychotic symptoms appear to be auditory hallucinations, delusions and thought disorder (Callagy et al., 2000), although occasionally catatonic motor changes can present (Reif et al., 2003). In older patients, ANCL may also present with a frontotemporal dementia-like picture (Zini et al., 2008), or with the hyperorality and sexual disinhibition characteristic of Kluver-Bucy syndrome (Alonso-Navarro et al., 2005). Neuropsychological impairments are common, often with a mixed frontal/subcortical picture of psychomotor slowing, impaired new learning and executive and attentional impairments (Hinkebein and Callahan, 1997; Zini et al., 2008). 
Sensitivity to the motor side effects of neuroleptic medication complicates the treatment of ACNL psychosis, with an increased propensity towards EPSE including dystonia (Gospe and Jankovic, 1986; Hinkebein and Callahan, 1997) and neuroleptic malignant syndrome (Reif et al., 2003; Vercammen et al., 2003). This sensitivity has been attributed to a combination of subcortical neuropathology and muscle membrane pathology (Reif et al., 2003). The treatment of psychosis, notwithstanding motor side effects, is usually with neuroleptic medication although electroconvulsive treatment has proven effective in a number of cases (Reif et al., 2003; Tobo et al., 1984). 


\section{ALPHA MANNOSIDOSIS}

In type II alpha mannosidosis (AM; OMIM: 248500) AM, which presents in later childhood or adulthood, the predominant features are cerebellar ataxia, hearing loss, neuropsychological impairment and retinopathy (Gutschalk et al., 2004). MRI scanning shows periventricular T2-hyperintensities in white matter (Gutschalk et al., 2004; Vite et al., 2001), which has been suggested to be secondary to demyelination (Dietemann et al., 1990) although is more likely to be an effect of myelin vacuolation (Sung et al., 1977). Cortical and cerebellar atrophy is also not uncommon in type II patients (Ara et al., 1999; Gutschalk et al., 2004). Diagnosis is established by the combination of a suggestive urinary pattern of oligosaccharides and demonstration of significantly reduced enzyme activity in leukocytes or cultured skin fibroblasts, and the only treatment option is bone marrow transplantation (Sun and Wolfe, 2001).

As in some other lysosomal disorders, patients with type II AM may be diagnosed with schizophrenia prior to the onset of frank neurological symptomatology (Seidl et al., 2004), or psychosis may follow the development of other symptoms (Gutschalk et al., 2004). Malm et al described a series of 45 patients over the age of fifteen, and found clearly diagnosable mental illness in $25 \%$, with the majority presenting with a psychotic disorder characterised by delusions, hallucinations, confusion and a prolonged period of post-psychotic somnolence (Malm et al., 2005). Psychosis in AM often presents with "organic" features, such as concurrent cognitive and neurological signs at the time of presentation. 


\section{FABRY DISEASE}

Fabry disease (FD; OMIM: 301500) causes accumulation of the glycolipid globotriaosylceramide (Gb3) in blood vessels and other tissues (Schiffmann, 2009), resulting in a range of end-organ vascular disease (Mehta et al., 2009; Mehta, 2009). Brain MRI often reveals subcortical ischemia in basal ganglia, brainstem, thalamus, and particularly periventricular white matter (Reisin et al., 2011).

Depressive disorders, often meeting criteria for a severe clinical depression, occur in up to half of all FD patients. The first series of FD patients highlighted an elevated rate of depression in both hemizygous males and female carriers (Grewal, 1993; Sadek et al., 2004). More recent systematic studies of larger cohorts have shown rates of major depression as high as 60\% (Cole et al., 2007; Laney et al., 2010; Schermuly et al., 2011). Depression and anxiety in FD patients predicts significant impairment in social and vocational functioning (Bouwman et al., 2011; Laney et al., 2010). There is no clear link between white matter lesion load and depression (Schermuly et al., 2011), although depression in FD appears to be predicted by the persistence of chronic pain and anhidrosis into adulthood (Cole et al., 2007). There is very little data on the response to antidepressants in this group. Psychosis has been occasionally described (Shen et al., 2007), although it is unclear whether this is causally related to the CNS pathology of FD (Gairing et al., 2011). Neuropsychologically, FD patients are frequently normal (Low et al., 2007) but may demonstrate attentional and executive deficits (Schermuly et al., 2011; Segal et al., 2010), commensurate with the effects of subcortical cerebrovascular disease. 


\section{ACUTE INTERMITTENT PORPHYRIA}

Acute intermittent porphyria (AIP; OMIM: 176000) has a lengthy historical association with mental illness. The periodic "madness" of King George III has been attributed to AIP (Ho et al., 2003), with the illness also implicated in Van Gogh's psychiatric history (Rose, 2006). AIP has been shown to be significantly overrepresented in large samples of psychiatric inpatients, at a rate up to 50-200x higher than the general population (McEwin et al., 1972; Tishler et al., 1985). The "classical triad" consists of abdominal pain, psychiatric disturbance, and peripheral neuropathies during episodes, although psychiatric symptoms alone may be the single presenting feature. Of clinically symptomatic patients, psychiatric disturbance occurs up to half of all cases (Crimlisk, 1997), half of which are psychotic episodes (Santosh and Malhotra, 1994), although depression, anxiety and delirium may also be the main presenting syndrome (Santosh and Malhotra, 1994). The intermittent "attacks" of neuropsychiatric disturbance may result in a misdiagnosis of schizophrenia (Crimlisk, 1997), and occasionally psychosis is the sole initial manifestation (Crimlisk, 1997; Ellencweig et al., 2006; Kumar, 2012). Additionally, because of the high likelihood of abdominal pain during periods of acute distress, patients may be diagnosed with a somatoform disorder or histrionic personality disorder (Ellencweig et al., 2006).

Although porphobilinogen (PBG) and amino-levulinic acid (ALA) accumulation is thought to be neurotoxic (Pierach and Edwards, 1978), exactly how this results in neuropsychiatric disturbance is unclear. Explanatory hypotheses have included oxidative stress, vascular change and demyelination, although it may be that ALA's structural similarity to GABA results in impaired release of GABA from synapses of GABAergic inhibitory neurons (Muller and Snyder, 1977), and reductions in heme dependent enzymes resulting in increased serotonin turnover and reduced nitric oxide activity (Meyer et al., 1998).

Psychopharmacological management of AIP involves judicious use of medication that will not worsen the biochemical deficit, which for psychosis includes chlorpromazine and droperidol, fluoxetine or sertraline for depression, lithium for mania, and lorazepam, triazolam and temazepam for anxiolysis and sedation (Holroyd and Seward, 1999). 


\section{MAPLE SYRUP URINE DISEAE}

In the milder forms of maple syrup urine disease (MSUD; OMIM: 248600) that present in adulthood, altered leucine metabolism alters astrocyte function (Funchal et al., 2005; Yudkoff et al., 1996) and induces neuronal apoptosis (Jouvet et al., 2000). Elevated leucine can block the transport across the blood-brain barrier of other large, neutral amino acids (LNAAs), including precursors of most monoamines, causing significant disruptions to dopaminergic, noradrenergic, serotonergic and histaminergic metabolism and thus neurotransmission (Zinnanti et al., 2009). Altered BCAA metabolism also results in depletion of gluatamate, GABA and aspartate, significantly altering excitatory/inhibitory neurotransmission across the CNS (Korein et al., 1994; Zinnanti et al., 2009). The BCAA-restricted diet also results in chronic cerebral valine deficiency, which itself may impair neuronal and oligodendrocyte function (Strauss et al., 2010). As a result, MSUD patients with poor dietary management will show reduced synaptogenesis and dendritic arborisation, and dysmyelination (Kamei et al., 1992; Kinney et al., 1994; Prensky and Moser, 1966) and, in acute metabolic crisis, cerebral edema (Strauss and Morton, 2003). These pathological changes may manifest on MRI as reductions in grey matter volume, abnormal T2 signal in white matter, and diffusion restriction (Jan et al., 2003; Schonberger et al., 2004) and altered spectroscopy during metabolic decompensation (Jan et al., 2003).

As in PKU, the advent of dietary restriction has modified illness course significantly, allowing survival of MSUD patients well into adulthood, albeit with a suggestion of subtle cognitive deficits and an elevated rate of some neuropsychiatric disorders (le Roux et al., 2006). MSD patients who transition to adulthood may have impaired neurological and psychosocial outcomes. Many may be left with subtle pyramidal and extrapyramidal signs (Carecchio et al., 2011) and as in a number of metabolic disorders where childhood dietary restriction is essential, MSUD patients perceive a significant strain from dietary management and resultant peer isolation, in addition to an impact on intimate/family relationships, education and employment (Packman et al., 2012; Simon et al., 2007). As in PKU, adult neuropsychological impairment appears more related to the age at institution of, and adherence to, dietary treatment (Hilliges et al., 1993; Hoffmann et al., 2006; Kaplan et al., 1991). 
Despite strict metabolic control, many children suffer from attentional-deficit disorders, whereas adolescents and adults commonly present with depression and anxiety (Strauss and Morton, 2003). Limited neurocognitive data exists, although it is suggestive of executive and attentional deficits, with impairments to nonverbal reasoning and spatial functioning (le Roux et al., 2006; Walsh and Scott, 2010). 


\section{UREA CYCLE DISORDERS}

The hyperammonemia that characterises urea cycle disorders (UCDs) causes hyperglutaminemia in the CNS, leading to cerebral edema and astrocytic swelling (Norenberg et al., 2005), altered axonal function and growth (Braissant et al., 2002) and NMDA-mediated excitotoxicity (Gropman et al., 2007; Robinson et al., 1995). MRI during the acute phase may show cerebral edema, particularly on T2-weighted imaging; repeated episodes of hyperammonemia may result in atrophy and gliosis visible on MRI (Gaspari et al., 2003; Panlaqui et al., 2008), and asymptomatic patients with most demonstrate alterations to white matter in frontal and parietal regions subserving executive and working memory functioning (Gropman, 2010). Patients with deficient arginase show alterations to corticospinal tracts (Oldham et al., 2010).

In older children/adolecents or adults, the presentation may be of recurrent episodes of encephalopathy, or with a more chronic encephalopathy; there may be a history of meat avoidance/refusal, and episodic headaches, vomiting, extreme lethargy and altered consciousness in the setting of metabolic stress or protein load (Legras et al., 2002; Nassogne et al., 2005). Arginase deficiency is the exception, as it presents with progressive spasticity and dementia. Psychiatric presentations in UCDs may initially occur as behavioural disturbance, with development to frank psychosis, and then acute encephalopathy (Belanger-Quintana et al., 2003; Eather et al., 2006; Lien et al., 2007; Nassogne et al., 2005; Thurlow et al., 2010). Affected or carrier females may present with adult-onset illness, particularly in the setting of pregnancy, and postpartum presentations may be misdiagnosed as postpartum psychosis (Enns et al., 2005; Fassier et al., 2011; Peterson, 2003; Tonini et al., 2011). In patients where acute-onset psychosis and confusion is associated with vomiting, lethargy, and seizures or other neurological symptoms, elevated plasma ammonia is crucial in excluding or confirming a UCD.

Sodium valproate is known to result in hyperammonemic encephalopathy, and as it is used as a mood stabiliser in psychiatric patients, it needs to be used carefully in patients with an atypical presentation of psychiatric illness, particularly when associated with confusion, lethargy and gastrointestinal symptoms as numerous case 
reports exist of severe medical compromise in this clinical circumstance (Bogdanovic et al., 2000; Chopra et al., 2012). 


\section{DISORDERS OF HOMOCYSTEINE METABOLISM}

In homocystinuria (OMIM: 236200), the accumulation of homocysteine and methionine, two sulphur-containing amino acids (SCAAs) in the CNS alters the release of monoamines (Selema et al., 1997) and may effect neurotoxicity via agonism of NMDA receptors (Schurr et al., 1993). Brain imaging may show leukodystrophy secondary to disrupted myelination (Vatanavicharn et al., 2008). While isolated case reports have identified patients with psychosis and homocystinuria (Bracken and Coll, 1985; Eschweiler et al., 1997; Li and Stewart, 1999; Ryan et al., 2002), studies investigating large case series of patients have reported that personality disorder, behavioural disturbance (such as aggression), depression and obsessive compulsive disorder are the most common psychiatric findings and that aggression and behavioural disturbances were commoner in patients with mental retardation (Abbott et al., 1987).

Methylenetetrahydrofolate reductase (MTHFR) deficiency (OMIM: 236250) has been strongly associated with psychosis in its less severe form, which presents in adolescents and adults (Birnbaum et al., 2008; Michot et al., 2008), and may result in impairment to myelination (Engelbrecht et al., 1997) and dopamine synthesis (Muntjewerff et al., 2008). Notably, the C677T variant of the MTHFR gene, with causes a 35\% reduction in MTHFR function, has been associated with an increased risk for schizophrenia in some (Arinami et al., 1997; Regland et al., 1997; Reif et al., 2005) but not all (Kunugi et al., 1998) populations; two recent meta-analyses suggest it confers a $70 \%$ increased risk of schizophrenia (Muntjewerff et al., 2006), which may be part of a broader vulnerability for both mood and psychotic disorders (Peerbooms et al., 2011). 


\section{PHENYLKETONURIA}

In phenylketonuria (PKU; OMIM: 261600), two metabolic processes affect the CNS. Elevated cerebral phenylalanine (Phe) levels inhibit tyrosine and tryptophan hydroxylase, altering monoaminergic neurotransmitter synthesis (particularly dopamine), but also reduce protein and cholesterol synthesis, impair synaptogenesis and alter glutamatergic transmission (de Groot et al., 2010; van Spronsen et al., 2009). Reduced large neutral amino acid (LNAA) availability results in reduced protein synthesis, impaired oligodendrocyte development and function, and severely disrupts normal neurodevelopment (Dyer, 1999; Hoeksma et al., 2009; van Spronsen et al., 2009). While altered cholesterol and protein synthesis particularly affect myelination, as evidenced by human post-mortem and in vivo MRI studies (Bauman and Kemper, 1982; Bick et al., 1991). Hypomyelination occurs in untreated PKU and in earlytreated patients, this appears to relate to intramyelinic edema (Anderson and Leuzzi, 2010). Increased T2 signal on MRI scanning is seen in most patients in frontal and parieto-occipital white matter (Cleary et al., 1994), and diffusion and spectroscopy imaging demonstrates altered diffusion and an increase in cerebral Phe that tightly correlates with serum Phe levels (Manara et al., 2009; Scarabino et al., 2009), particularly in anterior white matter (Christ et al., 2010b). Functional MRI has demonstrated impaired functional connectivity within and between pre-frontal cortical regions (White et al., 2010). In animal PKU models, hypomyelination has been partially restored with dietary phenylalanine restriction (Joseph and Dyer, 2003), and reversal of T2 signal abnormalities has been shown with a return to dietary management (Cleary et al., 1995).

Early-treated patients are described as showing elevated rates of depression, anxiety disorders (particularly agoraphobia), attention-deficit disorder and more non-specific psychosocial adjustment issues in adolescence when compared to matched healthy individuals (Brumm et al., 2010). Poor metabolic control, or early discontinuation, are associated with a higher incidence of behavioural problems in childhood (Holtzman et al., 1986; Smith et al., 1988). PKU patients who discontinued treatment in middle childhood demonstrate elevated rates of anxiety and mood disorders in adulthood (Koch et al., 2002; Ris et al., 1997; Waisbren and Zaff, 1994) and a persecutory stance in social contexts compared to continuously treated patients (Waisbren and 
Zaff, 1994). These higher rates of psychiatric and cognitive illness appear to directly negatively affect psychosocial outcomes (Gentile et al., 2010). A much higher proportion of PKU sufferers remain unmarried, childless, and/or living with their parents (Simon et al., 2008).

From a cognitive perspective, untreated patients will show mental retardation (with IQ<50) and developmental delay (Scriver and Kaufman, 2001). Much of the cognitive impairment can be attenuated with dietary control, although even early-treated patients may have subtle reductions in IQ, executive and attentional impairment (Weglage et al., 1996), although non-executive impairment is less consistently present (Janzen and Nguyen, 2010). The degree of dietary control in early-treated patients has a significant impact on ultimate cognitive outcome (Christ et al., 2010a; Gonzalez et al., 2011). However, perhaps less than $20 \%$ of adults maintain dietary control throughout adulthood (Walter et al., 2002), with the impact of diet on social interactions being a particular impediment to adherence (Cazzorla et al., 2012). Discontinuation in adult life is associated with poorer educational, socioeconomic and health outcomes (Koch et al., 2002), but re-engagement of "lost" patients may lead to improved outcomes (Burton and Leviton, 2010). 


\section{THE ORIGIN OF NEUROPSYCHIATRIC ILLNESS IN INBORN ERRORS OF METABOLISM}

As we have seen in the preceding section, metabolic disorders that result in neuropsychiatric illness alter CNS function and/or structure via a number of neuropathological processes. We postulate that the causality of psychiatric illness is the result of two processes: 1. The interruption of childhood/early adulthood neurodevelopmental trajectories in progressive illness, 2. The acute alteration of monaminergic or excitatory/inhibitory neurotransmitter systems in acute or episodic illness.

\section{Altered Neurodevelopment in Progressive Metabolic Illness}

For a number of disorders, different mutations can disrupt protein function to varying degrees, with severe disruption causing more severe impairment in neuronal function, and thus early onset of illness - usually in infancy or early childhood and a rapid course. Conversely, when function is only mildly disrupted, onset may be much later, such as late adolescence or early adulthood. As exemplified by progressive neurometabolic disorders such as MLD and NPC, the nature of the presentation relates to the relative maturity of the underlying $\mathrm{CNS}$ and the nature of the neurodevelopmental processes that are currently underway when neuronal function becomes significantly impaired (Hyde et al., 1992; Walterfang et al., 2006a)\{Shaw, $2010 \# 416$ \}. An understanding of neurodevelopment in adolescence and early adulthood, the period of onset of most mental illness, is thus crucial to understanding how metabolic disorders can lead to major psychiatric disorders.

In adolescence, the human brain undergoes great structural change, driven by a number of late neurodevelopmental processes. Grey matter reductions occur throughout the brain in a back-to-front direction, initially in sensorimotor, then association, and finally higher-order cortical areas such as pre-frontal and superior parietal cortex (Gogtay et al., 2004), with similar changes also occurring in subcortical regions (Sowell et al., 2002), putatively driven by a pruning of the overproliferation of synapses that occurs in early childhood and then again in early puberty (Zecevic and Rakic, 2001). This reduction in grey matter is matched by a 
linear increase in white matter, which continues through adolescence and adulthood (Bartzokis et al., 2003; Sowell et al., 2003), and which is driven by increasing myelination of cortico-cortical connections between prefrontal regions and between dorsolateral prefrontal cortex and temporal, parietal and occipital association areas (Fuster, 2002; Gogtay et al., 2004; Paus et al., 1999).

The long association fibres connecting frontal and temporal cortex are crucial in this period. Disrupted frontotemporal connectivity is thought to be central to the neurobiology of schizophrenia (Benes et al., 1994), and white matter disorders that disrupt these connections are particularly psychotogenic (Walterfang et al., 2005), although altered myelination may also occur in major mood disorders (Regenold et al., 2007). The refinement of prefrontal function allows a number of executive cognitive functions to mature and/or develop during this period, including processing speed, working memory, self-regulation, and cognitive control (Tau and Peterson, 2010). Myelination, and the refinement of cortico-cortical and cortico-subcortical connectivity, is affected in MLD, ALD, NPC, CTX, AM, AIP, MSUD, homocysteine metabolism disorders and PKU. Interference in this normal process is likely to underpin the elevated rate of mood and psychotic disorders, in addition to executive impairment, in these metabolic disorders. This is particularly exemplified in the leukodystrophies that present in adolescence or adulthood such as MLD and ALD, where rates of major mental illness such as psychosis or mood disorders occur in one quarter to one half of patients (Hyde et al., 1992; Rosebush et al., 1999).

These metabolic disorders lead to a disruption to macroconnectivity, whereby long association corticocortical and cortico-subcortical fibres are disrupted. The high-level temporal synchrony between these regions that is required for reality testing and behavioural and emotional regulation is compromised. This type of dysconnectivity is thought to be central to the pathogenesis of schizophrenia (Friston and Frith, 1995; Walterfang et al., 2006c), and schizophrenia-like psychoses are frequent presentations of metabolic illness (Sedel et al., 2007). Given the aforementioned widespread developmental synaptodendritic changes that occur during late adolescence and early adulthood, disruption of microconnectivity i.e connectivity between neurones may be a further pre-disposing factor to psychosis. Disturbed microconnectvity has been described as a possible neurodevelopmental "pathway" to schizophrenia (McGlashan 
and Hoffman, 2000). The dendritic changes in GM2 gangliosidosis (Purpura and Suzuki, 1976; Walkley et al., 1990) and consequent disruption in microconnectivity may underpin the elevated rates of psychosis in this disorder (Frey et al., 2005; Gravel et al., 1995; Neudorfer et al., 2005) while in a disorder such as NPC, where both micro- and macroconnectivity are impaired (Walterfang et al., 2010; Walterfang et al., 2012b), the rates of psychosis are even higher (Walterfang et al., 2006a).

Significant alterations to the dopaminergic system occur during this developmental period and largely involve the frontal cortex. Increases in dopaminergic fibre and dopamine transporter density (Kalsbeek et al., 1988; Spear, 2000) and differential (striatal > prefrontal) dopamine receptor pruning (Spear, 2000) leads to a relative dominance of the mesocortical dopaminergic system (Davey et al., 2008). Synaptic plasticity, pruning and myelination are partially dependent on dopaminergic innervation so that the refinement of cortico-cortical connections depends on the integrity of this system (Gurden et al., 1999).

A similar overproduction of other monaminergic receptors, which are then pruned and refined, also occurs in adolescence (Brenhouse and Andersen, 2011; Lidow and Rakic, 1992). Developmental disruption of monoaminergic systems contributes to the development of mood disorders (Davey et al., 2008) as well as psychosis (Di Forti et al., 2007). Inhibitory GABA-ergic and glutamatergic systems show ongoing changes, with a steady linear increase in levels of the former across adolescence (Lidow and Rakic, 1992) and substantial pruning from their early adolescent peak of NMDA receptors in frontotemporal regions (Insel et al., 1990).

Disruption to the dopaminergic system occurs in MSUD (Zinnanti et al., 2009) and disorders of homocysteine metabolism (Selema et al., 1997), but is perhaps most central to PKU (de Groot et al., 2010; Puglisi-Allegra et al., 2000), where prefrontal depletion appears to directly disrupt the development of dopamine-dependent executive functioning. Other monoaminergic systems are variably affected by MSUD (Zinnanti et al., 2009) and PKU (de Groot et al., 2010; Puglisi-Allegra et al., 2000). Given that reduced or dysregulated transmission in monoaminergic systems is integral to anxiety and depression (Gorman et al., 2002; Ruhe et al., 2007), these alterations to 
monoaminergic availability may underpin the higher prevalence of anxiety and depression in these metabolic disorders.

This model represents a shift away from a more traditional "neurodegenerative" model of neuropsychiatric illness, whereby mental disorders are described as resulting from the impaired function or loss of specific neuronal populations that have largely matured and which subserve mental functions such as reality testing or emotional regulation. Whilst psychiatric disorders do not infrequently occur in neurodegenerative disorders such as cortical and subcortical dementias, the vast majority of psychiatric disorders have their onset in adolescence or early adulthood, largely a distinct epoch from that in which the majority of neurodegenerative disorders have their onset. Secondly, as can be seen in disorders which have a varying age of onset of illness dependent on the degree of metabolic disturbance, such as NPC or MLD, when illness presents later in life, the presentation is more likely to be of a dementing-type illness rather than a typical psychiatric illness such as schizophrenialike psychosis, major depression or bipolar disorder. Additionally, a neurodegenerative process can disrupt a normal neurodevelopmental trajectory, as these are not discrete processes and can interact if neurodegeneration occurs within the timeframe of ongoing neurodevelopment. Thus, whilst typical neurodegeneration alone may present with neuropsychiatric illness in a proportion of patients with metabolic disorders, it is most likely to be the disruption of neurodevelopmental trajectories that results in typical psychiatric illness.

\section{Neurotransmitter Disruption in Acute/Episodic Illness}

In addition to those metabolic disorders that impact upon neurodevelopment, a number of metabolic disorders are associated with episodic but potentially reversible metabolic disturbances in the setting of an otherwise largely intact and normallydeveloped CNS. In disorders such as AIP, MSUD or the UCDs, acute decompensation can occur in the setting of particular metabolic states, such as situations requiring increased protein or heme synthesis, or when dietary management of a metabolic illness lapses or is disrupted.

These disorders result in acute alterations to the balance between excitatory and inhibitory systems via alteration of GABAergic and/or NMDA-mediated 
glutamatergic transmission, and/or alteration of monoaminergic transmission involving dopamine, serotonin or noradrenaline. Acute alteration of the excitatory/inhibitory balance between GABAergic and glutamatergic systems is exemplified by anti-NMDA receptor encephalitis gamma-hydroxy butyric acid (GHB) intoxication. The former is a paraneoplastic syndrome that causes acute-onset psychosis, frequently catatonic, in mostly young women (Dalmau et al., 2011), and its psychotogenic effects relate to acute loss of NMDA receptors that disrupt glutamatergic transmission (Hughes et al., 2010). Similarly, potent NMDA antagonists such as phencyclidine and ketamine can produce psychotic symptoms, potentially by secondary dysregulation of prefrontal and striatal dopaminergic systems (Javitt, 2007). Similarly, alterations of the GABAergic system have been implicated in substance-induced psychosis (Cagnin et al., 2011; Kruszewski et al., 2009) and delirium, particularly that secondary to alcohol withdrawal (Hughes, 2009). Thus, rapid dysregulation of either or both of these systems may result in psychosis and/or an acute confusional state, such as that seen in UCDs (Nassogne et al., 2005), MSUD (Strauss and Morton, 2003) and AIP (Muller and Snyder, 1977).

Similarly, monoaminergic depletion or reduced turnover can occur in a number of metabolic disorders, such as AIP (Meyer et al., 1998), MSUD (Zinnanti et al., 2009), or in untreated PKU (de Groot et al., 2010). Animal studies show that depression can result from acute depletion of dopamine (Santiago et al., 2010) and dopamine depleting agents used for movement disorders not infrequently cause depression (Chen et al., 2012a). Similarly, noradrenaline depletion has been reliably shown to lead to depression or depressive relapse (Miller et al., 1996). Both depression and anxiety can also be caused by serotonin depletion (Fernandez and Gaspar, 2012). Thus, the elevated rates of anxiety and depression seen in many of these disorders is not unexpected. Although the effect of depletion on different monoaminergic systems is complex, with interactions between different monoaminergic systems that occur differentially in different circuits (and which also interact with glutamatergic and GABAergic systems), disruption in these systems - particularly secondary to reduced monoaminergic synthesis or availability - is likely to result in alterations to mood, anxiety levels, and thus behaviour. 


\section{MANAGEMENT OF NEUROPSYCHIATRIC DISTURBANCE}

Management of neuropsychiatric disturbance in metabolic syndromes is generally symptomatic. For many disorders, little clear treatment data exists, and clinicians will generally treat a secondary psychiatric syndrome with the standard psychotropic medications: antidepressants for depression and anxiety; antipsychotics for psychosis; antipsychotics and mood stabilisers for mania and antipsychotics and/or benzodiazepines for agitation. However, a number of caveats apply in the management of neuropsychiatric symptoms in the setting of metabolic illness.

Metabolic disorders that disrupt neurodevelopment can result in psychiatric syndromes that are at initially, or may later become, treatment-resistant. This has been well-described in ALD (Rosebush et al., 2010), MLD (Hermle et al., 1997) and Niemann-Pick type C disease (Walterfang et al., 2006a; Walterfang et al., 2009a). It may be that secondary or "organic" psychiatric illness is less likely to respond to traditional treatments as the underpinning neurobiology of secondary presentations differs from the primary psychiatric illness in which the particular treatment has shown to be beneficial. A phenocopy of an illness does not guarantee that both the phenocopy and the primary illness will respond to the same treatments. Additionally, as many of these illnesses are progressive, patients may be initially responsive to treatment but less responsive to treatment over time as neurobiological change ensues. Furthermore, treatment response may depend on the maintained integrity of brain systems outside those thought to be disrupted in psychosis. If these systems become illness-affected, then this may impact upon illness presentation treatment response (Hyde et al., 1992). This is not uncommon in progressive disorders that result in secondary psychiatric syndromes, particularly as frank dementia supervenes (Walterfang et al., 2009b).

The second main issue relates to an increased propensity for side effects of psychiatric treatments, particularly dopamine blockers used to treat psychosis. If metabolic disorders affect the striatum, then these patients will have a significantly elevated rate of extra-pyramidal side effects. This has been well-described in TSD (Manor et al., 1997; Rosebush et al., 1995; Streifler et al., 1989), ACNL (Gospe and Jankovic, 1986; Hinkebein and Callahan, 1997) and NPC (Sandu et al., 2009). The anticholinergic 
side-effects of many antipsychotics and some antidepressants may worsen already compromised cognition in patients with moderate to advanced illness, as may the sedation caused by many of these medications' antihistaminic effects. Thus, careful consideration of agent choice is crucial in treating patients with secondary psychiatric syndromes, to minimise motor and cognitive side effects that may worsen the concomitant neurological manifestations of the underlying metabolic disorder.

Medications used to manage psychiatric symptoms such as aggression, agitation or mood elevation may also directly impact upon the underlying metabolic condition. The greatest caution should be exercised with valproate, which can precipitate or worsen the clinical presentation of AIP (Crimlisk, 1997) or UCDs (Bogdanovic et al., 2000; Chopra et al., 2012). Other porphyrogenic psychotropic medications which should be avoided include carbamazepine and imipramine. It has been suggested that tricyclic antidepressants and phenothiazines may worsen the underlying biochemical deficit of TSD (Hurowitz et al., 1993). In these circumstances however, there are generally a number of other available pharmacological options, including modern selective serotonergic antidepressants for depression and anxiety, and atypical antipsychotics for psychosis, mania and acute agitation (Walterfang et al., 2009b).

The most important treatment consideration in psychiatric presentations of metabolic disease is the detection of - and, where possible, institution of treatment for - the underlying disorder. In a patient presenting for the first time with a psychiatric syndrome, a metabolic disorder should be suspected when:

1. There is a significant family history of metabolic or other neurological disorder

2. The presentation of psychiatric symptoms occurs co-incident with neurological, cognitive or other systemic symptoms that suggest a more widespread neurological or systemic disease

3. The course is episodic and triggered by specific conditions that result in metabolic stress such as surgery, elevated protein intake or fever (Sedel et al., 2007).

If clinicians are aware of the aforementioned disorders and how they present, they can initiate either a specialist referral or commence an investigative path including brain 
MRI, examination of biofluids for specific metabolic intermediates or endproducts, or direct testing for enzymatic disorders. Sedel et al have described a useful diagnostic algorithm for both acute and chronic presentations of secondary psychiatric illness in a previous version of JIMD (Sedel et al., 2007). Accurate diagnosis may allow treatment and attenuation of the primary disorder, which may itself result in abatement of the psychiatric syndrome and reduce the requirement for psychotropic medication. 


\section{CONCLUSION}

A number of metabolic disorders can present at differing illness timepoints with major psychiatric illness. For many progressive disorders that present in adolescence or early adulthood, the disruption of late neurodevelopmental processes - which occur during the period of greatest vulnerability to major mental illness - appear to underpin the development of psychiatric illness. Disruption to myelination, and the resultant impairments in cortico-cortical and subcortical connectivity that ensue, is common to many of these disorders. For a range of other disorders that can cause acute metabolic disruption, disruption to inhibitory/excitatory neurotransmission, or monoaminergic neurotransmitter turnover and availability, appears to cause acute presentations of psychiatric illness. An awareness of these disorders, and the nature of how they may present, can allow clinicians to accurately diagnose a secondary psychiatric illness and institute appropriate treatment for the underlying disorder. 


\section{REFERENCES}

Abbott, M. H., et al., 1987. Psychiatric manifestations of homocystinuria due to cystathionine beta-synthase deficiency: prevalence, natural history, and relationship to neurologic impairment and vitamin B6-responsiveness. Am J Med Genet. 26, 959-69.

Alonso-Navarro, H., et al., 2005. [Kluver-Bucy syndrome as the initial symptom of adult-type ceroid lipofuscinosis (Kufs' disease)]. Rev Neurol. 40, 93-8.

Anderson, P. J., Leuzzi, V., 2010. White matter pathology in phenylketonuria. Mol Genet Metab. 99 Suppl 1, S3-9.

Ara, J., et al., 1999. Neurological impairment in alpha mannosidosis: a longitudinal clinical and MRI study of a brother and sister. Childs Nerv Syst. 15, 369-371.

Argov, Z., Navon, R., 1984. Clinical and genetic variations in the syndrome of adult GM2 gangliosidosis resulting from hexosaminidase A deficiency. Annals of neurology. 16, 14-20.

Arinami, T., et al., 1997. Methylenetetrahydrofolate reductase variant and schizophrenia/depression. Am J Med Genet. 74, 526-8.

Augustine, A., et al., 1993. Adult neuronal ceroid lipofuscinosis presenting with psychiatric symptoms: a case report. Int J Psychiatry Med. 23, 315-322.

Backman, M., et al., 2005. Psychiatric symptoms of children and adolescents with juvenile neuronal ceroid lipofuscinosis. J Intell Dis Res. 49, 25-32.

Bartzokis, G., et al., 2003. White matter structural integrity in healthy aging adults and patients with Alzheimer disease: a magnetic resonance imaging study. Archives of neurology. 60, 393-8.

Bauman, M. L., Kemper, T. L., 1982. Morphologic and histoanatomic observations of the brain in untreated human phenylketonuria. Acta Neuropathol. 58, 55-63.

Belanger-Quintana, A., et al., 2003. Hyperammonaemia as a cause of psychosis in an adolescent. Eur J Pediatr. 162, 773-5.

Benes, F. M., et al., 1994. Myelination of a key relay zone in the hippocampal formation occurs in the human brain during childhood, adolescence, and adulthood. Arch Gen Psychiatry. 51, 477-84.

Berginer, V., et al., 1994. Magnetic resonance imaging in cerebrotendinous xanthomatosis: a prospective clinical and neuroradiological study. Neurol Sci. 122, 102-108.

Berginer, V., et al., 1988. Psychiatric disorders in patients with cerebrotendinous xanthomatosus. Am J Psychiatry. 145, 354-357.

Berkovic, S., et al., 1988. Kuf's disease: a critical re-appraisal. Brain. 111, 27-62.

Bick, U., et al., 1991. Disturbed myelination in patients with treated hyperphenylalaninaemia: evaluation with magnetic resonance imaging. Eur $\mathbf{J}$ Pediatr. 150, 185-9.

Birnbaum, T., et al., 2008. Methylenetetrahydrofolate reductase deficiency (homocystinuria type II) as a rare cause of rapidly progressive tetraspasticity and psychosis in a previously healthy adult. Journal of neurology. 255, 18456.

Black, D. N., et al., 2003. Metachromatic leukodystrophy: a model for the study of psychosis. The Journal of neuropsychiatry and clinical neurosciences. 15, 28993. 
Bogdanovic, M. D., et al., 2000. Late onset heterozygous ornithine transcarbamylase deficiency mimicking complex partial status epilepticus. J Neurol Neurosurg Psychiatry. 69, 813-5.

Bouwman, M. G., et al., 2011. Impact of growing up with Fabry disease on achievement of psychosocial milestones and quality of life. Mol Genet Metab. 104, 308-13.

Braak, H., Braak, E., 1993. Pathoarchitectonic pattern of iso- and allocortical lesions in juvenile and adult neuronal ceroid lipofuscinoses. J Inher Metabol Dis. 16, 259-262.

Bracken, P., Coll, P., 1985. Homocystinuria and schizophrenia. Literature review and case report. J Nerv Ment Dis. 173, 51-5.

Braissant, O., et al., 2002. Ammonium-induced impairment of axonal growth is prevented through glial creatine. J Neurosci. 22, 9810-20.

Breen, L., et al., 1981. Juvenile Niemann-Pick disease with vertical supranuclear opthalmoplegia. Arch Neurol. 38, 388-390.

Brenhouse, H. C., Andersen, S. L., 2011. Developmental trajectories during adolescence in males and females: a cross-species understanding of underlying brain changes. Neuroscience and biobehavioral reviews. 35, 1687-703.

Brumm, V. L., et al., 2010. Psychiatric symptoms and disorders in phenylketonuria. Mol Genet Metab. 99 Suppl 1, S59-63.

Burton, B. K., Leviton, L., 2010. Reaching out to the lost generation of adults with early-treated phenylketonuria (PKU). Mol Genet Metab. 101, 146-8.

Byun, K., et al., 2011. Alteration of the CNS pathway to the hippocampus in a mouse model of Niemann-Pick, type $\mathrm{C}$ disease. J Chem Neuroanat. 42, 39-44.

Cagnin, A., et al., 2011. gamma-Hydroxybutyric acid-induced psychosis and seizures. Epilepsy Behav. 21, 203-5.

Callagy, C., et al., 2000. Adult neuronal ceroid lipofuscinosis (Kufs' disease) in two siblings of an Irish family. Clin Neuropathol. 19, 109-118.

Campo, J., et al., 1998. Psychosis as a presentation of physical disease in adolescence: a case of Niemann-Pick disease typc C. Dev Med Child Neurol. 40, 126-129.

Carecchio, M., et al., 2011. Movement disorders in adult surviving patients with maple syrup urine disease. Mov Disord. 26, 1324-8.

Castellote, A., et al., 1995. MR in adrenoleukodystrophy: atypical presentation as bilateral frontal demyelination. AJNR. American journal of neuroradiology. $16,814-5$.

Cazzorla, C., et al., 2012. Application of the WHOQOL-100 for the assessment of quality of life of adult patients with inherited metabolic diseases. Mol Genet Metab. 106, 25-30.

Chang, C. C., et al., 2010. Multi-parametric neuroimaging evaluation of cerebrotendinous xanthomatosis and its correlation with neuropsychological presentations. BMC neurology. 10, 59.

Charles, N., et al., 1990. Dementia and psychiatric disorders in Kufs disease. Rev Neurol (Paris). 146, 752-756.

Chen, J. J., et al., 2012a. Tetrabenazine for the treatment of hyperkinetic movement disorders: a review of the literature. Clin Ther. 34, 1487-504.

Chen, Q., et al., 2012b. Fluoxetine-responsive depression in a Chinese cerebrotendinous xanthomatosis. General hospital psychiatry. 34, 578 e1-4.

Chopra, A., et al., 2012. Valproate-induced hyperammonemic encephalopathy: an update on risk factors, clinical correlates and management. General hospital psychiatry. 34, 290-8. 
Christ, S. E., et al., 2010a. Executive function in early-treated phenylketonuria: profile and underlying mechanisms. Mol Genet Metab. 99 Suppl 1, S22-32.

Christ, S. E., et al., 2010b. Disruption of prefrontal function and connectivity in individuals with phenylketonuria. Mol Genet Metab. 99 Suppl 1, S33-40.

Cleary, M. A., et al., 1994. Magnetic resonance imaging of the brain in phenylketonuria. Lancet. 344, 87-90.

Cleary, M. A., et al., 1995. Magnetic resonance imaging in phenylketonuria: reversal of cerebral white matter change. J Pediatr. 127, 251-5.

Cole, A. L., et al., 2007. Depression in adults with Fabry disease: a common and under-diagnosed problem. Journal of inherited metabolic disease. 30, 943-51.

Constantinidis, J., et al., 1992. The adult and a new late adult forms of neuronal ceroid lipofuscinosis. Acta Neuropathol. 83, 461-468.

Crimlisk, H. L., 1997. The little imitator--porphyria: a neuropsychiatric disorder. J Neurol Neurosurg Psychiatry. 62, 319-28.

D'Incerti, L., 2000. MRI in neuronal ceroid lipofuscinosis. Neurol Sci. 21, S71-S73.

Dalmau, J., et al., 2011. Clinical experience and laboratory investigations in patients with anti-NMDAR encephalitis. Lancet Neurol. 10, 63-74.

Davey, C. G., et al., 2008. The emergence of depression in adolescence: development of the prefrontal cortex and the representation of reward. Neuroscience and biobehavioral reviews. 32, 1-19.

de Groot, M. J., et al., 2010. Pathogenesis of cognitive dysfunction in phenylketonuria: review of hypotheses. Mol Genet Metab. 99 Suppl 1, S86-9.

De Stefano, N., et al., 2001. Magnetic resonance imaging and spectroscopic changes in brains of patients with cerebrotendinous xanthomatosis. Brain. 124, 121-31.

Di Forti, M., et al., 2007. Risk factors for schizophrenia--all roads lead to dopamine. Eur Neuropsychopharmacol. 17 Suppl 2, S101-7.

Dietemann, J., et al., 1990. MR findings in mannosidosis. Neuroradiology. 33, 485487.

Dotti, M., et al., 1994. Cerebrotendinous xanthomatosis (van Bogaert-Scherer-Epstein disease): CT and MR findings. AJNR. 15, 1721-1726.

Dotti, M., et al., 1991. Cerebrotendinous xanthomatosis as a multisystem disease mimicking premature ageing. Dev Neurosci. 13, 371-376.

Dyer, C., 1999. Pathophysiology of phenylketonuria. Ment Retard Dev Disabil Res Rev. 5, 104-112.

Eather, G., et al., 2006. Carbamyl phosphate synthase deficiency: diagnosed during pregnancy in a 41-year-old. J Clin Neurosci. 13, 702-6.

Edwin, D., et al., 1990. Cognitive impairment in adult-onset adrenoleukodystrophy. Molecular and chemical neuropathology / sponsored by the International Society for Neurochemistry and the World Federation of Neurology and research groups on neurochemistry and cerebrospinal fluid. 12, 167-76.

Elleder, M., et al., 1985. Niemann-Pick disease type C. Study on the nature of the cerebral storage process. Acta Neuropathol. 66, 325-366.

Ellencweig, N., et al., 2006. Acute intermittent porphyria: psychosis as the only clinical manifestation. Isr J Psychiatry Relat Sci. 43, 52-6.

Elstein, D., et al., 2008. Neurocognitive testing in late-onset Tay-Sachs disease: a pilot study. Journal of inherited metabolic disease. 31, 518-23.

Engelbrecht, V., et al., 1997. MR and proton MR spectroscopy of the brain in hyperhomocysteinemia caused by methylenetetrahydrofolate reductase deficiency. AJNR. American journal of neuroradiology. 18, 536-9. 
Enns, G. M., et al., 2005. Postpartum "psychosis" in mild argininosuccinate synthetase deficiency. Obstet Gynecol. 105, 1244-6.

Eschweiler, G., et al., 1997. Postoperative psychosis in homocystinuria. Eur Psychiatry. 12, 98-101.

Fassier, T., et al., 2011. Misdiagnosed postpartum psychosis revealing a late-onset urea cycle disorder. Am J Psychiatry. 168, 576-80.

Federico, A., et al., 1991a. The clinical aspects of adult hexosaminidase deficiencies. Dev Neurosci. 13, 280-287.

Federico, A., et al., 1991b. The clinical aspects of adult hexosaminidase deficiencies. Developmental neuroscience. 13, 280-7.

Fernandez, S. P., Gaspar, P., 2012. Investigating anxiety and depressive-like phenotypes in genetic mouse models of serotonin depletion. Neuropharmacology. 62, 144-54.

Fink, J., et al., 1989. The clinical spectrum of Niemann-Pick disease type C. Neurology. 39, 104-01049.

Fluharty, A. L., 1990. The relationship of the metachromatic leukodystrophies to neuropsychiatric disorders. Molecular and chemical neuropathology / sponsored by the International Society for Neurochemistry and the World Federation of Neurology and research groups on neurochemistry and cerebrospinal fluid. 13, 81-94.

Frey, L., et al., 2005. The natural history of cognitive dysfunction in late-onset GM2 gangliosidosis. Arch Neurol. 62, 989-994.

Friston, K. J., Frith, C. D., 1995. Schizophrenia: a disconnection syndrome? Clinical neuroscience. 3, 89-97.

Funchal, C., et al., 2005. Morphological alterations and cell death provoked by the branched-chain alpha-amino acids accumulating in maple syrup urine disease in astrocytes from rat cerebral cortex. Cell Mol Neurobiol. 25, 851-67.

Fuster, J. M., 2002. Frontal lobe and cognitive development. J Neurocytol. 31, 37385.

Gairing, S., et al., 2011. Fabry's disease and psychosis: causality or coincidence? Psychopathology. 44, 201-4.

Gaspari, R., et al., 2003. Late-onset presentation of ornithine transcarbamylase deficiency in a young woman with hyperammonemic coma. Ann Emerg Med. 41, 104-9.

Gentile, J. K., et al., 2010. Psychosocial aspects of PKU: hidden disabilities--a review. Mol Genet Metab. 99 Suppl 1, S64-7.

German, D., et al., 2002. Neurodegeneration in the Niemann-Pick C mouse: glial involvement. Neurosci. 109, 437-450.

Goebel, H. H., Braak, H., 1989. Adult neuronal ceroid-lipofuscinosis. Clinical neuropathology. 8, 109-19.

Gogtay, N., et al., 2004. Dynamic mapping of human cortical development during childhood through early adulthood. Proc Natl Acad Sci U S A. 101, 8174-9.

Gonzalez, M. J., et al., 2011. Neurological complications and behavioral problems in patients with phenylketonuria in a follow-up unit. Mol Genet Metab. 104 Suppl, S73-9.

Gorman, J. M., et al., 2002. New developments in the neurobiological basis of anxiety disorders. Psychopharmacol Bull. 36 Suppl 2, 49-67.

Gospe, S. J., Jankovic, J., 1986. Drug-induced dystonia in neuronal ceroid lipofuscinosis. Pediatr Neurol. 2, 236-237. 
Grau, A., et al., 1997. Adult Niemann-Pick disease type C mimicking features of multiple sclerosis. J Neurol Neurosurg Psychiatr. 63, 522-525.

Gravel, R., et al., The GM2 Gangliosidoses. In: C. Scriber, et al., Eds.), The Metabolic and Molecular Basis of Inherited Disease. McGraw-Hill, New York, 1995, pp. 2839-2879.

Gravel, R., et al., The GM2 gangliosidoses. In: C. Scriver, et al., Eds.), The Metabolic and Molecular Bases of Inherited Disease. McGraw-Hill, New York, 2001, pp. 3827-3865.

Grewal, R. P., 1993. Psychiatric disorders in patients with Fabry's disease. Int J Psychiatry Med. 23, 307-12.

Gropman, A., 2010. Brain imaging in urea cycle disorders. Mol Genet Metab. 100 Suppl 1, S20-30.

Gropman, A. L., et al., 2007. Neurological implications of urea cycle disorders. Journal of inherited metabolic disease. 30, 865-79.

Guerrera, S., et al., 2010. Clinical relevance of brain volume changes in patients with cerebrotendinous xanthomatosis. Journal of neurology, neurosurgery, and psychiatry. 81, 1189-93.

Gurden, H., et al., 1999. Integrity of the mesocortical dopaminergic system is necessary for complete expression of in vivo hippocampal-prefrontal cortex long-term potentiation. Neuroscience. 94, 1019-27.

Gutschalk, A., et al., 2004. Adult alpha mannosidosis: clinical progression in the absence of demyelination. Neurology. 63, 1744-1746.

Guyant-Marechal, L., et al., 2005. Unusual cerebrotendinous xanthomatosis with fronto-temporal dementia phenotype. Am J Med Genet. 139, 114-117.

Hamner, M. B., 1998. Recurrent psychotic depression associated with GM2 gangliosidosis. Psychosomatics. 39, 446-8.

Harzer, K., et al., 1978. Neurovisceral lipidosis compatible with Niemann-Pick disease type $\mathrm{C}$ : morphological and biochemical studies of a late infantile case and enzyme and lipid assays in a prenatal case of the same family. Acta Neuropathol. 43, 97-104.

Hermle, L., et al., 1997. [Metachromatic leukodystrophy simulating schizophrenialike psychosis]. Nervenarzt. 68, 754-8.

Hilliges, C., et al., 1993. Intellectual performance of children with maple syrup urine disease. Eur J Pediatr. 152, 144-7.

Hinkebein, J., Callahan, C., 1997. The neuropsychology of Kuf's disease: a case of atypical early onset dementia. Arch Clin Neuropsychol. 12, 81-89.

Ho, N. C., et al., 2003. Famous people and genetic disorders: from monarchs to geniuses--a portrait of their genetic illnesses. Am J Med Genet A. 118A, 18796.

Hoeksma, M., et al., 2009. Phenylketonuria: High plasma phenylalanine decreases cerebral protein synthesis. Mol Genet Metab. 96, 177-82.

Hoffmann, B., et al., 2006. Impact of longitudinal plasma leucine levels on the intellectual outcome in patients with classic MSUD. Pediatr Res. 59, 17-20.

Holroyd, S., Seward, R. L., 1999. Psychotropic drugs in acute intermittent porphyria. Clin Pharmacol Ther. 66, 323-5.

Holtzman, N. A., et al., 1986. Effect of age at loss of dietary control on intellectual performance and behavior of children with phenylketonuria. The New England journal of medicine. 314, 593-8.

Hughes, E. G., et al., 2010. Cellular and synaptic mechanisms of anti-NMDA receptor encephalitis. J Neurosci. 30, 5866-75. 
Hughes, J. R., 2009. Alcohol withdrawal seizures. Epilepsy Behav. 15, 92-7.

Hurowitz, G., et al., 1993. Neuropsychiatric aspects of adult-onset Tay Sachs disease: two case reports with several new findings. J Neuropsychiatry Clin Neurosci. 5, 30-36.

Hyde, T. M., et al., 1992. Psychiatric disturbances in metachromatic leukodystrophy. Insights into the neurobiology of psychosis. Archives of neurology. 49, 401-6.

Inoue, K., Lupski, J. R., 2003. Genetics and genomics of behavioral and psychiatric disorders. Curr Opin Genet Dev. 13, 303-9.

Inoue, S., et al., 2012. A case of adult-onset adrenoleukodystrophy with frontal lobe dysfunction: a novel point mutation in the ABCD1 gene. Internal medicine. 51, 1403-6.

Insel, T. R., et al., 1990. The ontogeny of excitatory amino acid receptors in rat forebrain--I. N-methyl-D-aspartate and quisqualate receptors. Neuroscience. $35,31-43$.

Jan, W., et al., 2003. MR diffusion imaging and MR spectroscopy of maple syrup urine disease during acute metabolic decompensation. Neuroradiology. 45, 393-9.

Janzen, D., Nguyen, M., 2010. Beyond executive function: non-executive cognitive abilities in individuals with PKU. Mol Genet Metab. 99 Suppl 1, S47-51.

Javitt, D. C., 2007. Glutamate and schizophrenia: phencyclidine, N-methyl-Daspartate receptors, and dopamine-glutamate interactions. Int Rev Neurobiol. 78, 69-108.

Joseph, B., Dyer, C. A., 2003. Relationship between myelin production and dopamine synthesis in the PKU mouse brain. J Neurochem. 86, 615-26.

Josephs, K., et al., 2003. Adult-onset Niemann-Pick disease type C presenting with psychosis. JNNP. 74, 528-529.

Jouvet, P., et al., 2000. Branched chain amino acids induce apoptosis in neural cells without mitochondrial membrane depolarization or cytochrome c release: implications for neurological impairment associated with maple syrup urine disease. Mol Biol Cell. 11, 1919-32.

Kalsbeek, A., et al., 1988. Development of the dopaminergic innervation in the prefrontal cortex of the rat. J Comp Neurol. 269, 58-72.

Kamei, A., et al., 1992. Abnormal dendritic development in maple syrup urine disease. Pediatr Neurol. 8, 145-7.

Kaplan, P., et al., 1991. Intellectual outcome in children with maple syrup urine disease. J Pediatr. 119, 46-50.

Karten, B., et al., 2003. Trafficking of cholesterol from cell bodies to distal axons in Niemann Pick C1-deficiant neurons. J Biol Chem. 278, 4168-4175.

Kessler, R. C., et al., 2005. Lifetime prevalence and age-of-onset distributions of DSM-IV disorders in the National Comorbidity Survey Replication. Arch Gen Psychiatry. 62, 593-602.

Kinney, H. C., et al., 1994. Myelination in the developing human brain: biochemical correlates. Neurochem Res. 19, 983-96.

Koch, R., et al., 2002. Phenylketonuria in adulthood: a collaborative study. Journal of inherited metabolic disease. 25, 333-46.

Korein, J., et al., 1994. Maple syrup urine disease: clinical, EEG, and plasma amino acid correlations with a theoretical mechanism of acute neurotoxicity. Int $\mathbf{J}$ Neurosci. 79, 21-45.

Kornfeld, M., 2008. Neuropathology of chronic GM2 gangliosidosis due to hexosaminidase A deficiency. Clinical neuropathology. 27, 302-8. 
Kozian, R., et al., 2007. [Frontotemporal dementia in metachromatic leukodystrophy]. Fortschritte der Neurologie-Psychiatrie. 75, 549-51.

Kruszewski, S. P., et al., 2009. Gabapentin-induced delirium and dependence. J Psychiatr Pract. 15, 314-9.

Kumar, B., 2012. Acute intermittent porphyria presenting solely with psychosis: a case report and discussion. Psychosomatics. 53, 494-8.

Kunugi, H., et al., 1998. C677T polymorphism in methylenetetrahydrofolate reductase gene and psychoses. Mol Psychiatry. 3, 435-7.

Laney, D. A., et al., 2010. Social-adaptive and psychological functioning of patients affected by Fabry disease. Journal of inherited metabolic disease.

le Roux, C., et al., 2006. Neuropsychometric outcome predictors for adults with maple syrup urine disease. Journal of inherited metabolic disease. 29, 201-2.

Lee, Y., et al., 2002. Cerebrotendinous xanthomatosis with psychiatric disorder: report of three siblings and literature review. Chang Gung Med J. 25, 334-340.

Legras, A., et al., 2002. Late diagnosis of ornithine transcarbamylase defect in three related female patients: polymorphic presentations. Crit Care Med. 30, 241-4.

Lewandowska, E., et al., 2009. Kufs' disease: diagnostic difficulties in the examination of extracerebral biopsies. Folia Neuropathol. 47, 259-67.

Li, S. C., Stewart, P. M., 1999. Homocystinuria and psychiatric disorder: a case report. Pathology. 31, 221-4.

Lidow, M. S., Rakic, P., 1992. Scheduling of monoaminergic neurotransmitter receptor expression in the primate neocortex during postnatal development. Cereb Cortex. 2, 401-16.

Lien, J., et al., 2007. Fatal initial adult-onset presentation of urea cycle defect. Archives of neurology. 64, 1777-9.

Lipowski, Z. J., 1984. Organic brain syndromes: new classification, concepts and prospects. Can J Psychiatry. 29, 198-204.

Lossos, A., et al., 1997. Adult-onset Niemann-Pick type C disease: clinical, biochemical and genetic study. Arch Neurol. 54, 1536-1541.

Low, M., et al., 2007. Neurology of Fabry disease. Intern Med J. 37, 436-47.

Luda, E., Barisone, M. G., 2001. Adult-onset adrenoleukodystrophy: a clinical and neuropsychological study. Neurological Sciences. 22, 21-5.

MacDonald, J. T., et al., 1984. Adrenoleukodystrophy: early frontal lobe involvement on computed tomography. Journal of computer assisted tomography. 8, 12830.

MacQueen, G., et al., 1998. Neuropsychiatric aspects of the adult variant of TaySachs disease. J Neuropsychiatry Clin Neurosci. 10, 10-19.

Malm, D., et al., 2005. Psychiatric symptoms in mannosidosis. J Intell Dis Res. 49, 865-871.

Manara, R., et al., 2009. Brain MRI diffusion-weighted imaging in patients with classical phenylketonuria. Neuroradiology. 51, 803-12.

Manor, I., et al., 1997. Neuroleptic malignant syndrome with gangliosidosis type II. Biological psychiatry. 41, 1222-4.

March, P., et al., 1997. GABAergic neuroaxonal dystrophy and other cytopathological alterations in feline Niemann-Pick disease type C. Acta Neuropathol. 94, 164172.

McEwin, R., et al., 1972. A survey of porphyria among psychiatric patients. Med J Aust. 2, 303-6. 
McGlashan, T. H., Hoffman, R. E., 2000. Schizophrenia as a disorder of developmentally reduced synaptic connectivity. Arch Gen Psychiatry. 57, 63748.

Mehta, A., et al., 2009. Natural course of Fabry disease: changing pattern of causes of death in FOS - Fabry Outcome Survey. J Med Genet. 46, 548-52.

Mehta, A. B., 2009. Anderson-Fabry disease: developments in diagnosis and treatment. Int J Clin Pharmacol Ther. 47 Suppl 1, S66-74.

Meyer, U. A., et al., 1998. Acute porphyrias: pathogenesis of neurological manifestations. Semin Liver Dis. 18, 43-52.

Michot, J. M., et al., 2008. Psychosis, paraplegia and coma revealing methylenetetrahydrofolate reductase deficiency in a 56-year-old woman. J Neurol Neurosurg Psychiatry. 79, 963-4.

Miller, H. L., et al., 1996. Clinical and biochemical effects of catecholamine depletion on antidepressant-induced remission of depression. Arch Gen Psychiatry. 53, 117-28.

Moghadasian, M., et al., 2002. Cerebrotendinous xanthomatosis: a rare disease with diverse manifestations. Arch Neurol. 59, 527-529.

Muller, W. E., Snyder, S. H., 1977. delta-Aminolevulinic acid: influences on synaptic GABA receptor binding may explain CNS symptoms of porphyria. Ann Neurol. 2, 340-2.

Muntjewerff, J. W., et al., 2008. Polymorphisms in catechol-O-methyltransferase and methylenetetrahydrofolate reductase in relation to the risk of schizophrenia. Eur Neuropsychopharmacol. 18, 99-106.

Muntjewerff, J. W., et al., 2006. Homocysteine, methylenetetrahydrofolate reductase and risk of schizophrenia: a meta-analysis. Mol Psychiatry. 11, 143-9.

Nassogne, M. C., et al., 2005. Urea cycle defects: management and outcome. Journal of inherited metabolic disease. 28, 407-14.

Navon, R., et al., 1986. Hexosaminidase deficiency in adults. Am J Med Genet. 24, 179-196.

Neudorfer, O., et al., 2005. Late-onset Tay-Sachs disease: phenotypic characterization and genotypic correlation in 21 affected patients. Genet Med. 7, 119-123.

Nijssen, P. C., et al., 2009. Electroencephalography in autosomal dominant adult neuronal ceroid lipofuscinosis. Clin Neurophysiol. 120, 1782-6.

Norenberg, M. D., et al., 2005. Mechanisms of ammonia-induced astrocyte swelling. Metab Brain Dis. 20, 303-18.

Oates, C., et al., 1986. Movement disorders associated with chronic GM2 gangliosidosis: case report and review of the literature. Eur Neurol. 25, 154159.

Oldham, M. S., et al., 2010. Diffusion tensor imaging in arginase deficiency reveals damage to corticospinal tracts. Pediatr Neurol. 42, 49-52.

Ong, W., et al., 2001. Neurodegeneration in Niemann-Pick type C disease mice. Exp Brain Res. 141, 218-231.

Packman, W., et al., 2012. Young Adults with MSUD and Their Transition to Adulthood: Psychosocial Issues. J Genet Couns. 21, 692-703.

Palmeri, S., et al., 1994. Hypoplasia of the corpus callosum in Niemann-Pick type C disease. Neuroradiology. 36, 20-22.

Panlaqui, O. M., et al., 2008. Acute hyperammonemic encephalopathy in adult onset ornithine transcarbamylase deficiency. Intensive Care Med. 34, 1922-4.

Patel, P. J., et al., 1995. Adrenoleukodystrophy: CT and MRI findings. Pediatric radiology. 25, 256-8. 
Paus, T., et al., 1999. Structural maturation of neural pathways in children and adolescents: in vivo study. Science. 283, 1908-11.

Peerbooms, O. L., et al., 2011. Meta-analysis of MTHFR gene variants in schizophrenia, bipolar disorder and unipolar depressive disorder: evidence for a common genetic vulnerability? Brain Behav Immun. 25, 1530-43.

Peterson, D. E., 2003. Acute postpartum mental status change and coma caused by previously undiagnosed ornithine transcarbamylase deficiency. Obstet Gynecol. 102, 1212-5.

Pettersson-Yeo, W., et al., 2011. Dysconnectivity in schizophrenia: where are we now? Neuroscience and biobehavioral reviews. 35, 1110-24.

Pierach, C. A., Edwards, P. S., 1978. Neurotoxicity of delta-aminolevulinic acid and porphobilinogen. Exp Neurol. 62, 810-4.

Poll-The, B. T., Gartner, J., 2012. Clinical diagnosis, biochemical findings and MRI spectrum of peroxisomal disorders. Biochimica et Biophysica Acta. 1822, 1421-9.

Prensky, A. L., Moser, H. W., 1966. Brain lipids, proteolipids, and free amino acids in maple syrup urine disease. J Neurochem. 13, 863-74.

Pressey, S. N., et al., 2012. Early glial activation, synaptic changes and axonal pathology in the thalamocortical system of Niemann-Pick type $\mathrm{C} 1$ mice. Neurobiol Dis. 45, 1086-100.

Puglisi-Allegra, S., et al., 2000. Dramatic brain aminergic deficit in a genetic mouse model of phenylketonuria. Neuroreport. 11, 1361-4.

Purpura, D., Suzuki, K., 1976. Distortion of neuronal geometry and formation of aberrant synopsis in neuronal storage disease. Brain Res. 116, 1-21.

Rauschka, H., et al., 2006. Late-onset metachromatic leukodystrophy: genotype strongly influences phenotype. Neurology. 67, 859-63.

Regenold, W. T., et al., 2007. Myelin staining of deep white matter in the dorsolateral prefrontal cortex in schizophrenia, bipolar disorder, and unipolar major depression. Psychiatry Res. 151, 179-88.

Regland, B., et al., 1997. Homozygous thermolabile methylenetetrahydrofolate reductase in schizophrenia-like psychosis. J Neural Transm. 104, 931-41.

Reider-Grosswasser, I., Bornstein, N., 1987. CT and MRI in late-onset metachromatic leukodystrophy. Acta neurologica Scandinavica. 75, 64-9.

Reif, A., et al., 2005. Homocysteinemia as well as methylenetetrahydrofolate reductase polymorphism are associated with affective psychoses. Prog Neuropsychopharmacol Biol Psychiatry. 29, 1162-8.

Reif, A., et al., 2003. Neuroleptic malignant syndrome in Kuf's disease. J Neurol Neurosurg Psychiatry. 74, 385-387.

Reisin, R. C., et al., 2011. Brain MRI findings in patients with Fabry disease. J Neurol Sci. 305, 41-4.

Renshaw, P., et al., 1992. Electroconvulsive therapy treatment of depression in a patient with adult GM2 gangliosidosis. Ann Neurol. 31, 342-344.

Ris, M. D., et al., 1997. Adult psychosocial outcome in early-treated phenylketonuria. Journal of inherited metabolic disease. 20, 499-508.

Robinson, M. B., et al., 1995. Evidence of excitotoxicity in the brain of the ornithine carbamoyltransferase deficient sparse fur mouse. Brain Res Dev Brain Res. $90,35-44$.

Rose, F. C., 2006. Van Gogh's madness. Int Rev Neurobiol. 74, 253-69. 
Rosebush, P., et al., Psychosis associated with leukodystrophies. In: P. Sachdev, M. Keshavan, Eds.), Secondary Schizophrenia. Cambridge University Press, 2010, pp. 241-256.

Rosebush, P., et al., 1995. Late-onset Tay Sachs disease presenting as catatonic schizophrenia: diagnostic and treatment issues. J Clin Psychiatry. 56, 347-353.

Rosebush, P. I., et al., 1999. The neuropsychiatry of adult-onset adrenoleukodystrophy. The Journal of neuropsychiatry and clinical neurosciences. 11, 315-27.

Ruhe, H. G., et al., 2007. Mood is indirectly related to serotonin, norepinephrine and dopamine levels in humans: a meta-analysis of monoamine depletion studies. Mol Psychiatry. 12, 331-59.

Ryan, M. M., et al., 2002. Homocystinuria presenting as psychosis in an adolescent. J Child Neurol. 17, 859-60.

Sadek, J., et al., 2004. Psychiatric findings in four female carriers of Fabry disease. Psychiatr Genet. 14, 199-201.

Sandu, S., et al., 2009. Niemann-Pick disease type C1 presenting with psychosis in an adolescent male. Eur Child Adolesc Psychiatry. 18, 583-5.

Santiago, R. M., et al., 2010. Depressive-like behaviors alterations induced by intranigral MPTP, 6-OHDA, LPS and rotenone models of Parkinson's disease are predominantly associated with serotonin and dopamine. Prog Neuropsychopharmacol Biol Psychiatry. 34, 1104-14.

Santosh, P. J., Malhotra, S., 1994. Varied psychiatric manifestations of acute intermittent porphyria. Biological psychiatry. 36, 744-7.

Saudubray, J. M., 2009. Neurometabolic disorders. Journal of inherited metabolic disease. 32, 595-6.

Sayit, E., et al., 2002. Comparison of brain perfusion SPECT and MRI findings in children with neuronal ceroid-lipofuscinosis and in their families. Ann Nucl Med. 16, 201-206.

Scarabino, T., et al., 2009. Phenylketonuria: white-matter changes assessed by 3.0-T magnetic resonance (MR) imaging, MR spectroscopy and MR diffusion. Radiol Med. 114, 461-74.

Schermuly, I., et al., 2011. Neuropsychiatric symptoms and brain structural alterations in Fabry disease. European journal of neurology : the official journal of the European Federation of Neurological Societies. 18, 347-53.

Schiffman, R., 1996. Niemann-Pick disease type C: from bench to bedside. JAMA. 276, 561-564.

Schiffmann, R., 2009. Fabry disease. Pharmacol Ther. 122, 65-77.

Schonberger, S., et al., 2004. Dysmyelination in the brain of adolescents and young adults with maple syrup urine disease. Mol Genet Metab. 82, 69-75.

Schreiber, S. S., Baudry, M., 1995. Selective neuronal vulnerability in the hippocampus--a role for gene expression? Trends Neurosci. 18, 446-51.

Schreiner, R., et al., 2000. Kuf's disease: a rare cause of early-onset dementia. Nervenarzt. 71, 411-415.

Schurr, A., et al., 1993. The neurotoxicity of sulfur-containing amino acids in energydeprived rat hippocampal slices. Brain Res. 601, 317-20.

Scriver, C., Kaufman, S., Hyperphenylalaninemia: phenylalanine hydroxylase deficiency. In: C. Scriver, et al., Eds.), The Metabolic and Molecular Bases of Inherited Disease. McGraw-Hill, New York, 2001, pp. 16671724. 
Sedel, F., et al., 2007. Psychiatric manifestations revealing inborn errors of metabolism in adolescents and adults. Journal of inherited metabolic disease. 30, 631-41.

Segal, P., et al., 2010. Psychiatric and cognitive profile in Anderson-Fabry patients: a preliminary study. Journal of inherited metabolic disease. 33, 429-36.

Seidl, U., et al., 2004. Unusual course of alpha mannosidosis with symptoms of paranoid-hallucinatory psychosis. Nervenarzt. 76, 335-338.

Selema, G., et al., 1997. Sulphur-containing amino acids modulate noradrenaline release from hippocampal slices. J Neurochem. 68, 1534-41.

Shapiro, E. G., et al., 1994. Characteristics of the dementia in late-onset metachromatic leukodystrophy. Neurology. 44, 662-5.

Shapiro, S., 1983. Depression in a patient with dementia secondary to cerebrotendinous xanthomatosis. J Nerv Ment Dis. 171, 568-571.

Shen, Y. C., et al., 2007. Psychosis in a patient with Fabry's disease and treatment with aripiprazole. Prog Neuropsychopharmacol Biol Psychiatry. 31, 779-80.

Shulman, L., et al., 1995a. Psychosis as the initial manifestation of adult-onset Niemann-Pick disease type C. Neurology. 45, 1739-1743.

Shulman, L., et al., 1995b. Case 1, 1995: Psychosis, dementia, chorea, ataxia and supranuclear gaze dysfunction. Mov Disord. 10, 257-262.

Simon, E., et al., 2008. Evaluation of quality of life and description of the sociodemographic state in adolescent and young adult patients with phenylketonuria (PKU). Health Qual Life Outcomes. 6, 25.

Simon, E., et al., 2007. Social outcome in adults with maple syrup urine disease (MSUD). Journal of inherited metabolic disease. 30, 264.

Smith, I., et al., 1988. Behavior disturbance in 8-year-old children with early treated phenylketonuria. Report from the MRC/DHSS Phenylketonuria Register. J Pediatr. 112, 403-8.

Soffer, D., et al., 1995. The neuropathology of cerebrotendinous xanthomatosis revisited: a case report and review of the literature. Acta neuropathologica. 90, 213-20.

Sowell, E. R., et al., 2003. Mapping cortical change across the human life span. Nat Neurosci. 6, 309-15.

Sowell, E. R., et al., 2002. Development of cortical and subcortical brain structures in childhood and adolescence: a structural MRI study. Dev Med Child Neurol. 44, 4-16.

Spear, L. P., 2000. The adolescent brain and age-related behavioral manifestations. Neuroscience and biobehavioral reviews. 24, 417-63.

Strauss, K. A., Morton, D. H., 2003. Branched-chain Ketoacyl Dehydrogenase Deficiency: Maple Syrup Disease. Curr Treat Options Neurol. 5, 329-341.

Strauss, K. A., et al., 2010. Classical maple syrup urine disease and brain development: principles of management and formula design. Mol Genet Metab. 99, 333-45.

Streifler, J., et al., 1989. Psychiatric features of adult GM2 gangliosidosis. Br J Psychiatry. 155, 410-413.

Streifler, J., et al., 1993. Brain imaging in late-onset GM2 gangliosidosis. Neurology. 43, 2055-2058.

Su, C. S., et al., 2010. Cerebrotendinous xanthomatosis patients with and without parkinsonism: clinical characteristics and neuroimaging findings. Movement disorders : official journal of the Movement Disorder Society. 25, 452-8. 
Sullivan, D., et al., 2005. Bipolar disorder and Niemann-Pick disease type C. Am J Psychiatry. 165, 1021-1022.

Sun, H., Wolfe, J., 2001. Recent progress in lysosomal alpha mannosidase and its deficiency. Exp Mol Med. 33, 1-7.

Sung, J., et al., 1977. Mannosidosis: pathology of the nervous system. J Neuropathol Exp Neurol. 36, 807-820.

Suzuki, K., 1991. Neuropathology of late onset gangliosidoses. A review. Developmental neuroscience. 13, 205-10.

Tau, G. Z., Peterson, B. S., 2010. Normal development of brain circuits. Neuropsychopharmacology. 35, 147-68.

Tedeschi, G., et al., 1998. Proton magnetic resonance spectroscopic imaging in the clinical evaluation of patients with Niemann-Pick type C disease. J Neurol Neurosurg Psychiatry. 65, 72-79.

Thurlow, V. R., et al., 2010. Fatal ammonia toxicity in an adult due to an undiagnosed urea cycle defect: under-recognition of ornithine transcarbamylase deficiency. Ann Clin Biochem. 47, 279-81.

Tishler, P. V., et al., 1985. High prevalence of intermittent acute porphyria in a psychiatric patient population. Am J Psychiatry. 142, 1430-6.

Tobo, M., et al., 1984. Familial occurrence of adult-type neuronal ceroid lipofuscinosis. Arch Neurol. 41, 1091-1094.

Tonini, M. C., et al., 2011. Headache and neuropsychic disorders in the puerperium: a case report with suspected deficiency of urea cycle enzymes. Neurological Sciences. 32 Suppl 1, S157-9.

Turpin, J., et al., 1991. Type C Niemann-Pick disease: supranuclear opthalmoplegia assocated with deficient biosynthesis of cholesterol esters. Rev Neurol (Paris). 147, 28-34.

van Spronsen, F. J., et al., 2009. Brain dysfunction in phenylketonuria: is phenylalanine toxicity the only possible cause? Journal of inherited metabolic disease. 32, 46-51.

Vanier, M., 1999. Lipid changes in Niemann-Pick disease type C brain: personal experience and review of the literature. Neurochem Res. 24, 481-489.

Vatanavicharn, N., et al., 2008. Reversible leukoencephalopathy with acute neurological deterioration and permanent residua in classical homocystinuria: A case report. Journal of inherited metabolic disease.

Vercammen, L., et al., 2003. Neuroleptic malignant syndrome in juvenile neuronal ceroid lipofuscinosis associated with low-dose risperidone therapy. Journal of inherited metabolic disease. 26, 611-2.

Vite, C., et al., 2001. Histopathology, electrodiagnostic testing and magnetic resonance imaging show significant peripheral and central nervous system myelin abnormalities in the cat model of alpha mannosidosis. J Neuropathol Exp Neurol. 60, 817-828.

Waisbren, S. E., Zaff, J., 1994. Personality disorder in young women with treated phenylketonuria. Journal of inherited metabolic disease. 17, 584-92.

Waldman, A., 1992. Sometimes when you hear hoofbeats... two cases of inherited metabolic diseases with initial presentation of psychiatric symptoms. J Neuropsychiatry Clin Neurosci. 4, 113-114.

Walkley, S., 1988. Pathobiology of neuronal storage disease. Int Rev Neurobiol. 29, 191-244. 
Walkley, S. U., et al., 1990. Initiation and growth of ectopic neurites and meganeurites during postnatal cortical development in ganglioside storage disease. Brain Res Dev Brain Res. 51, 167-78.

Wallon, D., et al., 2010. Clinical imaging and neuropathological correlations in an unusual case of cerebrotendinous xanthomatosis. Clinical neuropathology. 29, 361-4.

Walsh, K. S., Scott, M. N., 2010. Neurocognitive profile in a case of maple syrup urine disease. Clin Neuropsychol. 24, 689-700.

Walter, J. H., et al., 2002. How practical are recommendations for dietary control in phenylketonuria? Lancet. 360, 55-7.

Walterfang, M., et al., 2011. Size and shape of the corpus callosum in adult NiemannPick type $\mathrm{C}$ reflects state and trait illness variables. AJNR. American journal of neuroradiology. 32, 1340-6.

Walterfang, M., et al., 2010. White and gray matter alterations in adults with Niemann-Pick disease type C: a cross-sectional study. Neurology. 75, 49-56.

Walterfang, M., et al., 2006a. The neuropsychiatry of adult-onset Niemann-Pick type C disease. J Neuropsychiatry Clin Neurosci. 18, 158-170.

Walterfang, M., et al., 2009a. Gender dimorphism in siblings with schizophrenia-like psychosis due to Niemann-Pick disease type C. Journal of inherited metabolic disease.

Walterfang, M., et al., 2006b. The neuropsychiatry of Niemann-Pick type C disease in adulthood. The Journal of neuropsychiatry and clinical neurosciences. 18, 158-70.

Walterfang, M., et al., 2012a. Pontine-to-midbrain ratio indexes ocular-motor function and illness stage in adult Niemann-Pick disease type C. European journal of neurology : the official journal of the European Federation of Neurological Societies. 19, 462-7.

Walterfang, M., et al., The neuropsychiatry of neurometabolic and neuroendocrine disorders. In: B. Sadock, et al., Eds.), Kaplan and Sadock's Comprehensive Textbook of Psychiatry. Lippincott Williams and Wilkins, Philadelphia, 2009b, pp. 592-618.

Walterfang, M., et al., 2012b. Subcortical volumetric reductions in adult NiemannPick disease type C: a cross-sectional study. Am J Neuroradiol. In Press.

Walterfang, M., et al., 2005. Diseases of white matter and schizophrenia-like psychosis. The Australian and New Zealand journal of psychiatry. 39, 746-56.

Walterfang, M., et al., 2006c. Neuropathological, neurogenetic and neuroimaging evidence for white matter pathology in schizophrenia. Neuroscience and biobehavioral reviews. 30, 918-48.

Walterfang, M. A., et al., 2007. The neuropsychiatry of adrenomyeloneuropathy. CNS spectrums. 12, 696-701.

Weglage, J., et al., 1996. Deficits in selective and sustained attention processes in early treated children with phenylketonuria--result of impaired frontal lobe functions? Eur J Pediatr. 155, 200-4.

White, D. A., et al., 2010. Age-related decline in the microstructural integrity of white matter in children with early- and continuously-treated PKU: a DTI study of the corpus callosum. Mol Genet Metab. 99 Suppl 1, S41-6.

Wisniewski, K., et al., 2001. Neruonal ceoid lipofuscinoses: classification and diagnosis. Adv Genet. 45, 1-34.

Yudkoff, M., et al., 1996. Astrocyte leucine metabolism: significance of branchedchain amino acid transamination. J Neurochem. 66, 378-85. 
Zaroff, C., et al., 2004. Neuropsychological assessment of patients with late-onset GM2 gangliosidosis. Neurology. 62, 2283-2286.

Zecevic, N., Rakic, P., 2001. Development of layer I neurons in the primate cerebral cortex. J Neurosci. 21, 5607-19.

Zervas, M., et al., 2001. Neurons in Niemann-Pick type C accumulate gangliosides as well as unesterified cholesterol and undergo dendritic and axonal alterations. J Neuropathol Exp Neurol. 60, 49-64.

Zini, A., et al., 2008. Early-onset dementia with prolonged occipital seizures: an atypical case of Kufs disease. Neurology. 71, 1709-12.

Zinnanti, W. J., et al., 2009. Dual mechanism of brain injury and novel treatment strategy in maple syrup urine disease. Brain. 132, 903-18. 